\title{
Het gynaecologisch logboek voor arts-assistenten: kansen voor een portfolio?
}

\author{
S. Mahesh, K. Sijtsma, F. Scheele, B. Wolf, E.W. Driessen
}

\begin{abstract}
Samenvatting
Inleiding: Er zijn plannen om bij de opleiding tot gynaecoloog gebruik te maken van portfolio 'leren en toetsen'. In dat kader wilden wij vaststellen hoe het huidige logboek door geneeskundigen in opleiding (AGIO's) tot gynaecoloog en hun opleiders gebruikt wordt. Een tweede vraag betrof de motivatie om mee te werken aan verandering van het logboek in de richting van een portfolio.
\end{abstract}

Methode: Alle Nederlandse AGIO's obstetrie en gynaecologie werd gevraagd om een vragenlijst in te vullen. De lijst was opgedeeld in vier categorieën: het dagelijkse gebruik, de rol bij de evaluatie en beoordeling van de AGIO, verbetering of aanpassing van het huidige logboek en de mogelijkheid tot respons. Een 5-puntsschaal werd gebruikt. Co-variabelen waren het opleidingsjaar en het type opleidingsziekenhuis.

Resultaten: Van de 269 vragenlijsten werd 65\% (176) geretourneerd. De uitslagen van de vragenlijst waren voor (a) het bijhouden van het logboek: 3,2 (SD 1,3), (b) het denken dat de opleider veel waarde hecht aan het logboek: 2,9 (SD 1,1), (c) het gebruik bij evaluatiegesprekken: 2,6 (SD 1,4), (d) het gebruik bij het aftekenen van het autorisatieniveau: 2,0 (SD 1,1), (e) het beter inzicht krijgen in de eigen vorderingen: 2,7 (SD 1,2), (f) het gebruik om de opleider te wijzen op diens verplichtingen: 3,0 (SD 1,3), (g) als bewijs van vordering: 2,8 (SD 1,2), (h) een herziening van het logboek ten behoeve van toetsing: 3,8 (SD 1,4), (i) een herziening ten behoeve van het komend modulair opleidingssysteem: 4,0 (SD 1,0), en (j) een herziening ten behoeve van een autorisatiesysteem: 3,9 (SD 1,1). Een deel van de AGIO's benadrukte dat een verhoging van de administratieve tijdsinvesteringen moet worden vermeden.

Discussie en conclusie: Ongeveer de helft van de opleidingsassistenten Obstetrie en Gynaecologie gebruikt het logboek matig. Het plan om een portfolio te introduceren vraagt om een grondige voorbereiding en zal gepaard moeten gaan met een cultuurverandering binnen de discipline. De tijd die nodig is voor het bijhouden van een portfolio moet binnen redelijke proporties blijven. Het introduceren van portfolio 'leren en toetsen' vereist een goede begeleiding en motivatie van zowel de AGIO's als de opleiders en is gerechtvaardigd door de te verwachten meeropbrengsten (toegenomen zelfreflectie, gestructureerde beoordeling meerdere rollen). Wanneer het portfolio leidt tot een persoonlijk ontwikkelingsplan, dan kan dit leiden tot een hogere motivatie onder de AGIO's. (Mahesh S, Sijtsma K, Scheele F, Wolf B, Driessen EW. Het gynaecologisch logboek voor arts-assistenten: kansen voor een portfolio? Tijdschrift voor Medisch Onderwijs 2004;23(6):274-280.)

\section{Inleiding}

Het Centraal College Medische Specialismen (CCMS) heeft zich in december 2003 uitgesproken over de gewenste lijn van modernisering van de medisch-specialistische opleiding. Daarbij is onder andere be- sloten dat men per 1 januari 2006 bij de toetsings- en beoordelingsregelingen van de aankomend specialist gebruik dient te gaan maken van een portfolio. ${ }^{1}$ Naar aanleiding hiervan zal ook de Nederlandse Vereniging voor obstetrie en gynaecologie 
(NVOG) besluiten om bij de opleiding tot gynaecoloog gebruik te gaan maken van een portfolio, ter vervanging van het thans in gebruik zijnde logboek.

Waarom de overgang? De voornaamste reden voor de overgang van logboek naar portfolio is de gedachte dat de kwaliteit van de opleiding van AGIO's tot gynaecoloog zal verbeteren door het invoeren van reflectief leren. ${ }^{2}$ Met een portfolio gestructureerd rond de CanMEDS-rollen 3 zal de AGIO bovendien over een breder domein getoetst kunnen worden. ${ }^{4-5}$ Het huidige logboek voldoet minder aan deze doelen, omdat het maar weinig uitlokt tot zelfreflectie op de groei van competenties en dan alleen binnen het domein van medisch expert en wetenschapper.

Daar portfolio-leren niet alleen kwantitatief, maar ook kwalitatief verschilt van het bijhouden van een logboek, vroegen wij ons af wat de kansen voor een portfolio zouden zijn. Immers, het portfolio voegt de kwalitatieve dimensie toe en vraagt daarmee om extra inspanning. Wanneer het gebruik van het huidige logboek matig zou blijken te zijn, dan zou dat een moeilijke overgang naar het meer inspanning vereisende portfolio kunnen voorspellen. Wij onderzochten hoe het huidige logboek door de AGIO's en hun opleiders gebruikt wordt; er werd tevens gepolst of zij de noodzaak van verandering en uitbreiding van het huidige logboek tot een portfolio, zoals thans in voorbereiding is, onderschrijven.

\section{Het logboek van de NVOG}

Het huidige logboek wordt bij aanvang van de opleiding op diskette aan de AGIO's uitgereikt. Het is ook mogelijk het logboek elektronisch te downloaden vanaf de site van de NVOG. De doelstelling van dit logboek is de AGIO te helpen door de verschillende aspecten van de opleiding te rubriceren en te registreren. Hierdoor kan de AGIO de opleiders, het Consilium Obstetricum en de Medisch Specialisten Registratie Commissie (MSRC) informeren over de voortgang en het resultaat van de opleiding. ${ }^{6}$ Het bijhouden van dit logboek is verplicht gesteld in de vergadering van het Consilium in 1992. Het logboek stuurt aan op een zeer bondige registratie van de volgende items en hoofdstukken: verloskundige en gynaecologische verrichtingen, wetenschappenlijke verrichtingen, autorisatie en cursorisch onderwijs. Het logboek blijft eigendom van de AGIO en wordt bij het beëindigen van de opleiding, na kennisneming door de leescommissie van het Consilium, altijd teruggestuurd.

Het te gaan gebruiken portfolio verschilt in hoofdzaak van het logboek doordat er aandacht is voor de algehele competentie van de AGIO en voor de periodieke reflectie op de groei van competenties en taakstelling. ${ }^{7}$

\section{Methode}

Via de post werd aan alle Nederlandse AGIO's obstetrie en gynaecologie gevraagd om een enquête getiteld 'Het NVOGlogboek: hoe werkt het nu en waar willen de AGIO's naar toe?' over de rol van het huidige logboek in te vullen. De enquête bestond uit twaalf vragen, verdeeld in vier categorieën, waarvan drie luidden: 'Het dagelijkse gebruik van het logboek', 'De rol van het logboek bij zelfevaluatie en beoordeling van de AGIO' en 'De motivatie voor eventuele verbetering van het huidige logboek'. De vierde categorie was de mogelijkheid tot aanbevelingen (ruimte opengelaten voor het opschrijven van commentaar en aanvullende suggesties onder aan het formulier). Antwoorden op de eerste drie categorieën konden gegeven worden op een 5-puntsschaal. Co-variabelen waren het opleidingsjaar en het type opleidingsziekenhuis. Bij de vragenlijst was een retourenvelop gevoegd. 
$\mathrm{Na}$ een termijn van tien weken voor het accepteren van enquêtes, werd er telefonisch contact opgenomen met degenen (25 personen) die het formulier niet hadden ingevuld om te vragen waarom zij dat niet gedaan hadden. De sluitingstermijn was drie maanden na het versturen van de enquête.

\section{Analyse}

Voor de statistische analyse werd gebruik gemaakt van de Mokken-schaalanalyse. ${ }^{8}$ Voor deze analyse is gekozen omdat deze gebruik maakt van een index (aangeduid met $\mathrm{H}$, ook wel 'schaalbaarheidscoëfficiënt' genoemd). Deze index geeft aan hoe goed de items tezamen of in deelgroepen bij elkaar passen en tevens de mate waarin personen geordend kunnen worden op de totaalscore op de items. Een hogere positieve waarde van $\mathrm{H}$ voor een aantal items geeft aan dat hun onderlinge samenhang sterker is. De gemiddelde totaalscore van een groep geeft dan in sterkere mate aan wat de mening van de groep is over de kwestie waar de items gezamenlijk naar vragen; dit is een vorm van betrouwbaarheidsbepaling.

\section{Resultaten}

Van de 269 vragenlijsten werd 65\% (176) geretourneerd. Voor de uitslagen, zie figuur 1.

Voor de vragen a, b, c en d samen gold een schaalbaarheidscoëfficiënt $\mathrm{H}=0,35$ (zwakke schaal), voor de vragen e, $\mathrm{f}$ en $\mathrm{g}$ samen gold $\mathrm{H}=0,42$ (matig sterke schaal) en voor de vragen $h$, $i$, en $\mathrm{j}$ samen gold $\mathrm{H}=0,53$ (sterke schaal). ${ }^{8}$ Uit de bewerking met de Mokken-schaalanalyse bleken de vragen 3 en 5 over het dagelijks gebruik van het logboek minder betrouwbare antwoorden op te leveren.

Er waren geen aanwijsbare verschillen in score tussen de assistenten die bezig waren met hun opleidingsstage in een academisch ziekenhuis en die in een perifeer ziekenhuis. Wel was de respons hoger onder de assistenten werkend in de eerste drie jaar van hun opleiding: 69\% versus $31 \%$ respons onder assistenten in de opleidingsjaren vier tot en met zes.

De belangrijkste redenen voor nonrespons (gemeld bij telefonische navraag onder 25 AGIO's) waren: geen interesse (9\%), geen tijd (26\%) en vergeten (35\%). De overige $30 \%$ van het commentaar was vanwege de diversiteit niet goed te categoriseren en was minder informatief van aard.

De meest gehoorde aanbevelingen (op 94 van de 269 formulieren) waren in positieve zin: een goede leidraad voor inzicht van de te leren vaardigheden, een leidraad voor te verrichten ingrepen en het vertrouwen dat de opleider hier inzicht krijgt in het functioneren van de AGIO. In negatieve zin stond voorop dat de AGIO's (56 van 94) benadrukten dat een verhoging van de administratieve tijdsinvesteringen moet worden vermeden en dat het huidige logboek, vooral door 'te weinig tijd', niet functioneel implementeerbaar was in het dagelijks functioneren op de werkvloer.

\section{Discussie}

Het valt vooral op dat het dagelijkse gebruik van het huidige logboek onder de AGIO's obstetrie en gynaecologie matig is. De meerderheid van de AGIO's en mogelijk ook hun opleiders ervaart de rol van het logboek blijkbaar als minder zinvol voor gebruik bij evaluatiegesprekken, als bewijs van de vorderingen en voor beoordelingen. De meerderheid is van mening dat het niet het juiste middel is om inzichten te krijgen in de eigen vorderingen en gebruikt het maar zeer matig voor het aftekenen van het autorisatieniveau, wat juist een belangrijk doel zou moeten zijn van het logboek.

Bij het interpreteren van de Mokkenschaalanalyse ziet men een sterke schaal 

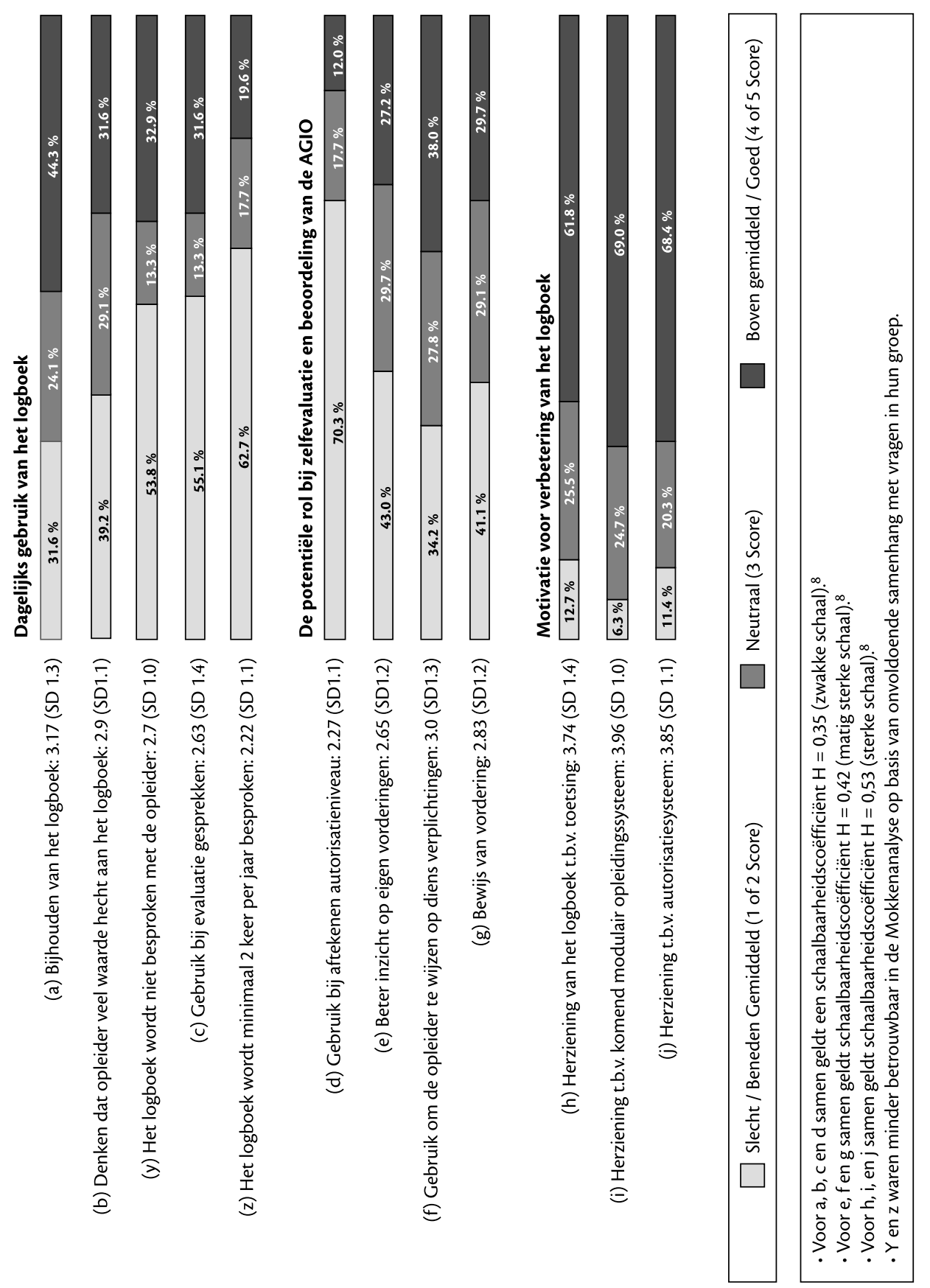

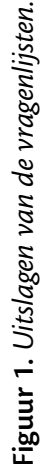


in de categorie betreffende de motivatie voor verbeteringen van het logboek. Uit deze hoge $\mathrm{H}$-waarde blijkt dat de gemiddelde totaalscores in de groep vragen naar de motivatie voor verbetering van het logboek betrouwbaar zijn gemeten. Omdat de gemiddelde scores in deze groep hoog zijn, kunnen we vaststellen dat een sterke motivatie voor verbetering van het logboek bestaat. In tegenstelling tot de gemeten bereidheid tot verandering, werd in de commentaren en aanvullende suggesties in meer dan helft van de gevallen aangegeven dat een grotere tijdsinvestering ongewenst is.

Op grond van de resultaten van de enquête vermoeden wij dat het de nodige overtuigingskracht onder de Nederlandse AGIO's obstetrie en gynaecologie zal vergen alvorens enthousiast gebruik gemaakt zal worden van een portfoliosysteem. Daarbij is het vooral de vraag of de investering in tijd en geld die nodig zal zijn om een systeem met een wellicht schoolser karakter en extra (papier)werk in te kunnen voeren, zal worden geaccepteerd.

Zou het kunnen dat het logboek matig wordt gebruikt, omdat er aan ontbreekt wat een portfolio misschien wel te bieden heeft? De AGIO's zouden juist behoefte kunnen hebben aan de mogelijkheden tot meer reflectie, zoals een portfolio die kan bieden. Voorstanders van de introductie van het portfolio stellen dat met name het reflectief leren en de beoordeling van de gestructureerde aandacht voor een breder competentiedomein belangrijke argumenten voor invoering zijn. Echter, wat uiteindelijk de doorslag zal gaan geven, gezien de resultaten in andere onderzoeken, is de bereidheid van de AGIO tot de introductie van en de participatie in het ontwikkelen van een veel arbeidsintensiever portfolio. ${ }^{9}$ Essentieel is dat de AGIO het werken aan het portfolio als nuttig er- vaart. Alleen dan is hij of zij bereid de benodigde inspanning te leveren.

Het succes van portfoliogebruik in de lerarenopleiding lijkt voor een belangrijk deel bepaald te worden door de mogelijkheid om met een persoonlijk ontwikkelingsplan te werken. ${ }^{10} \mathrm{Te}$ verwachten is dat de AGIO's een dergelijk persoonlijk ontwikkelingsplan aan de hand van portfoliobesprekingen heel aantrekkelijk zullen vinden. Met name wanneer dat gepaard kan gaan met een doelmatiger opleidingsschema, wat in een aantal gevallen zelfs kan resulteren in een verkorting van de opleiding.

Hoewel de kwaliteit van de geboden begeleiding van de AGIO in ons onderzoek geen variabele was, denken wij dat de invoering van portfoliomethoden ook een andere benadering vergt van de opleiders en de stafleden: zij dienen meer agogische vaardigheden te ontwikkelen. ${ }^{11-12}$ Hun rol wordt er meer een van coachen, begeleiden en reflecteren 10 in plaats van het overdragen van vakinhoudelijke kennis.

Daar 2006, de invoeringsdatum van het portfolio volgens het CCMS, nadert, zou er mogelijk een overgangsfase moeten worden geïntroduceerd. Een suggestie zou kunnen zijn om te beginnen met het in fasen aanpassen van het logboek van de NVOG aan de inzichten van deze tijd. Men kan dan een kleinschalig (over 2 á 3 CanMEDS-rollen, zoals medisch expert en manager) portfolio-'experiment' uitvoeren met gedocumenteerde zelfreflectie. De onderwerpen hiervoor moeten nog nader bepaald worden, liefst in overleg met de AGIO's. Voorts dient men reflectie en adequate feedback gemeengoed te maken, onder andere door het opleiden van opleiders. Als interimanalyse kan men vervolgens vaststellen hoe het gebruik, de reflectie en de feedback verlopen en hoe het portfolio door AGIO's en oplei- 
ders wordt gewaardeerd. Op grond van de hiermee verkregen gegevens kan men daarna besluiten of het portfolio moet worden uitgebouwd, om te beginnen voor de toetsing in de eerste drie opleidingsjaren, zoals voorgesteld door het CCMS, ${ }^{1}$ en voortwerkend aan het concept van het persoonlijke ontwikkelingsplan, wat zo attractief kan zijn voor de AGIO.

\section{Conclusie}

Onze enquête geeft een matig gebruik van het logboek aan. Een kort en bondig logboek is in de gynaecologenopleiding niet tot bloei gekomen. Het introduceren van en het omgaan met portfolio's zijn veeleisende en tijdrovende zaken voor zowel de AGIO als de opleider, en vragen om een grondige voorbereiding. Zowel de AGIO als de opleider zal zich eerst het portfoliosysteem eigen moeten maken voordat er succes van kan worden verwacht. De verandering die nodig is voor de bewijsvoering van groei in de verschillende rollen van de gynaecoloog en voor zelfreflectie is dan ook, mede gezien het huidige opleidingsklimaat en de opleidingscultuur, groot. Deze verandering zal mogelijk als schokkend worden ervaren binnen het opleidingssysteem voor gynaecologen.

Met het oog op de genoemde voordelen van met name een toegenomen zelfreflectie en de mogelijkheid van beoordeling binnen een groter domein, lijkt het ons dat de benodigde inspanningen zeker gerechtvaardigd worden door de te verwachten meeropbrengsten. Daarbij dient de tijd die nodig is voor het bijhouden van een portfolio binnen redelijke proporties te blijven. AGIO's zullen het gebruik van een portfolio waarschijnlijk aantrekkelijk gaan vinden wanneer dit leidt tot een persoonlijk ontwikkelingsplan, resulterend in een doelmatiger opleidingsschema en in een aantal gevallen misschien zelfs tot opleidingsverkorting.

\section{Dankbetuiging}

De auteurs danken de redactie en twee anonieme reviewers van dit tijdschrift voor hun commentaar op een eerdere versie van dit artikel.

\section{Literatuur}

1. KNMG. Brief 23-12-2003. Ref: ccms/03-439. Onderwerp: modernisering specialistische opleidingen.

2. KNMG. Bijlage 2 bij het 'Kaderbesluit CCMS medisch specialisten', als bedoeld in artikel B.6, tweede lid, 'Toetsings- en beoordelingsregelingen'.

3. The Royal College of Physicians and Surgeons of Canada. CanMEDS 2000. The Royal College of Physicians and Surgeons of Canada's Canadian medical education directions for specialists 2000 - project; 1996. http://rcpsc.medical.org/publications/index.php.

4. Wilkinson TJ, Challis M, Hobma SO, Newble DI, Parboosirgh JT, et al. The use of portfolios for assessment of the competence and performance of doctors in practice. Med Educ 2002;36(10):91824.

5. Lonka K, Slotte V, Halttunen M, Kurki T, Tiitinen A, Vaara L, et al. Portfolio's as a learning tool in obstetrics and gynaecology undergraduate training. Med Educ 2001;5(12):1097-8.

6. NVOG. Logboek opleiding Verloskunde \& Gynaecologie. www.nvog.nl.

7. Scheele F, Puyebroek JI, Wolf B, Schutte MF, Schade MI, et al. Toetsing in de opleiding tot gynaecoloog. Tijdschrift voor Medisch Onderwijs 2004;23(1):40-50.

8. Molenaar IW, Sijtsma K. User's manual MSP5 for Windows. A program for Mokken scale analysis for polytomous items. Groningen: iecProGAMMA; 2000.

9. Mathers NJ, Challis MC, Howe AC, Field NJ, et al. Portfolios in continuing medical education - effective and efficient? Med Educ 1999;33(7):52130.

10. Kortenhage F, Vasalos A. Niveau in reflectie: naar maatwerk in begeleiding. VELON Tijdschrift voor Lerarenopleiders 2002;23(1):29-37.

11. Raghoebar-Krieger HMJ, Sleijfer D, Bender W, Stewart RE, Popping R, et al. The reliability of logbook data of medical students: an estimation of interobserver agreement, sensitivity and specificity. Med Educ 2001;35:624-31.

12. Pearson DJ, Heywood P. Portfolio use in general practice vocational training: a survey of GP registrars. Med Educ 2004;35:87-95. 


\section{De auteurs:}

Mw. drs. S. Mahesh is arts-assistent in opleiding tot gynaecoloog in het AMC te Amsterdam.

Prof. dr. K. Sijtsma is psychometrist en hoogleraar Statistiek en Methode aan de Universiteit van Tilburg.

Prof. dr. F. Scheele is gynaecoloog en opleider Verloskunde en Gynaecologie in het Sint Lucas Andrea Ziekenhuis, en werkzaam t.b.v. onderwijs en opleiding aan het Onderwijsinstituut Geneeskunde VUMC te Amsterdam.

Dr. B. Wolf is kinderarts en opleider kindergeneeskunde in het Sint Lucas Andreas Ziekenhuis te Amsterdam.
Mw. drs. E.W. Driessen is psycholoog en onderwijskundige, werkzaam bij de Capaciteitsgroep Onderwijsontwikkeling en Onderwijsresearch van de Faculteit Geneeskunde, Universiteit van Maastricht.

\section{Correspondentieadres:}

Mw. drs. S. Mahesh, AMC, Afdeling Verloskunde \& Gynaecologie, Meibergdreef 9, 1105 AZ Amsterdam, tel: 0205669111,fax:020-6971651,s.mahesh@amc.uva.nl.

\section{Summary}

Introduction: In view of plans to introduce a portfolio in specialist training in obstetrics/gynaecology in the Netherlands, we addressed two questions: 1. How is the current logbook being used? and 2. Are all parties involved prepared to co-operate in working towards a change from logbook to portfolio?

Method: All residents in obstetrics/gynaecology were surveyed on the current use of the logbook, its role in assessment, possible improvements and suggestions for improvement. The residents responded to 12 questions on a five-point scale. Co-variables were year of training and type of teaching hospital.

Results: 269 questionnaires were sent out. The response rate was 65\% (176). The main results were as follows: a) regular use: 3.2 (SD 1.3); (b) perceived appreciation by the teaching professor: 2.9 (SD 1.1); use for: (c) appraisal: 2.6 (SD 1.4), (d) authorisation: 2.0 (SD 1.1), (e) self assessment 2.7 (SD 1.2), and (f) reminding the teaching professor of his obligations: 3.0 (SD 1.3); (g) evidence of progress: 2.8 (SD 1.2); need for revision of logbook: (h) for use in assessment 3.8 (SD 1.4), (i) for the coming modular training system 4.0 (SD 1.0), (j) to improve the authorisation system 3.9 (SD 1.1). Some residents emphasised the need to limit the amount of paperwork.

Discussion and conclusion: About half of the residents did not use the logbook adequately. The introduction of a portfolio in specialist training in obstetrics/ gynaecology will require careful preparation and a culture change within the discipline. The time investment in the portfolio must be limited. The introduction of portfolio learning and assessment will require information, support and motivation of residents and teaching professors. It is justified by the expected gain in self-reflection and structured assessment of several roles. If the portfolio leads to a personal development plan, it will result in increased motivation among residents. (Mahesh $S$, Sijtsma $K$, Scheele $F$, Wolf $B$, Driessen $E W$. The role of a logbook in specialist training in gynaecology in the Netherlands: time for change? Dutch Journal of Medical Education 2004;23(6):274-280.) 